7. If you like medical details we will show you on $x$-ray films what happens to stones made of cystine when their owners do and don't do what they are told.

\section{Treatment by Tablets of Sodium Bicarbonate}

We sometimes advise people to take these tablets in addition to doing the water-drinking routine, never instead of it. The tablets plus water-drinking probably work a little better than the water alone. However, they are more trouble, and there is always the possibility that they are not good for you if taken for a long time.
We therefore reserve their use for special situations and will not give you any without explaining this further.

REFERENCES

Crawhall, J. C., Scowen, E. F., and Watts, R. W. E. (1963). Brit. med. 7., 1,588 .

- (1964). Ibid., 1, 1411.

Dent, C. E., and Rose, G. A. (1951). Quart. 7. Med., 20, 205.

- and Senior, B. (1955). Brit. F. Urol., 27, 317.

.

Goldberg, A., Smith, J. A., and Lockhead, A. C. (1963). Brit. med. F., 1,1270 .

MacDougall, J. A. (1961). Ibid., 2, 819.

MacGregor, M. E. (1965). Proc. roy. Soc. Med. In press.

\title{
Use of Disinfectants in Hospitals
}

\section{A Report by the Public Health Laboratory Service Committee on the Testing and Evaluation of Disinfectants*}

Brit. med. 9., 1965, 1, 408-413

\section{Introduction}

This committee was set up in May 1961 to consider the evaluation of liquid antiseptics and disinfectants for hospital use. In particular three questions were thought to require answers: To what uses were these agents put? Into what categories could these uses be divided ? What tests were proper for each category ?

This task is not an easy one. It is probable that there will always be disagreement over matters of detail, and indeed rigid standardization may limit progress, but meanwhile disinfection policies for hospitals must be planned, and this communication is an attempt to give some guidance to those responsible.

\section{Present Usage}

A questionary was prepared in which 166 hospitals in England and Wales were asked about 53 possible uses for disinfectants. The replies were not easy to analyse, but two points emerged quite clearly. (a) In most hospitals no policy existed. A number of different disinfectants were used at many different strengths and often particular disinfectants were used for quite unsuitable purposes. (b) In a significant minority of hospitals a clear, if empirical, policy had succeeded in reducing the number of disinfectants to a very few. Some examples will illustrate these points.

Sluices.-At least 25 different disinfectants were used. The most popular were phenolics, which included lysol at dilutions between $1 / 20$ and $1 / 500$ and white fluids between $1 / 80$ and $1 / 600$. The next most popular were quaternary ammonium compounds, which were used at dilutions between $1 / 200$ and $1 / 6,000$, and chlorhexidine: both of these are quite unsuitable for this purpose (see Section 5).

Handwashing in Operating-theatres.-At least 20 different preparations were listed. In most replies no strength was given, but chlorhexidine $5 \%$ concentrate was used in dilutions between $1 / 20$ and $1 / 200$. Two hospitals stated that they used only "physical methods" but did not elucidate further.

- The members of the committee were: Sir Graham Wilson (chairman 1961-3), Dr. J. W. Howie (chairman 1963-4), Mr. H. Davis, C.B.E., Ph.D., F.R.I.C., Professor L. P. Garrod, Dr. R. J. Henderson, Mr. G. Sykes, M.Sc., F.R.I.C., Mr. A. H. Tomlinson, D.Phil,, Dr. J. C. Kelsey (secretary), Central Public Health Laboratory, Colindale Avenue, London N.W.9.
More generally, quaternaries and chlorhexidine were commonly used in situations where they could be rapidly inactivated by organic matter or in which their ineffectiveness against the tubercle bacillus could be a serious disadvantage.

The total number of agents reported as being used varied greatly between hospitals, for example:

\begin{tabular}{lcccc} 
& \multicolumn{3}{c}{ No. of Agents Used } \\
& Mode & & Range \\
For general use on inanimate objects & $\ldots$ & 8 & $\ldots$ & $3-23$ \\
For use on skin or mucous membranes & $\ldots$ & 6 & $\ldots$ & $0-14$
\end{tabular}

Appendix 1 gives the disinfectants which were most popular for various purposes.

This survey thus showed that in many hospitals disinfectants were used in an irrational way; this is undesirable for two reasons. First, the disinfectant may be ineffective, and therefore unsafe, either because it is inherently unsuitable or because it is used at too low a concentration. Secondly, very large sums of money may be wasted if an unnecessarily expensive disinfectant or an unnecessarily high concentration is used. From the information available it was not possible to calculate the actual cost to the Health Service of these misuses of disinfectants. In one group known to us the total annual cost of disinfectants was cut from $22 \mathrm{~s}$. $4 \mathrm{~d}$. to $12 \mathrm{~s}$. $2 \mathrm{~d}$. per bed by a relatively conservative rationalization. If this annual saving of 10s. per bed were applied to all non-mental beds in England and Wales at least $£ 125,000$ would be available for other purposes; this figure could easily be raised by more radical measures.

\section{Limitations and Scope of Liquid Chemical Antimicrobial Agents}

It is now generally accepted that only certain physical methods, such as heat or ionizing irradiation, can be relied on to kill all microbes with absolute certainty. Few liquid disinfectants will kill spores within a reasonable time or will kill viruses with certainty, and the efficacy of all is apt to be impaired by the presence of organic matter. Thus they should be used only when physical methods are impossible or impracticable.

Some of the uses to which disinfectants are commonly put are now examined. 
Liquid antibacterial agents are used in medical practice with two intentions, for sterilization and for disinfection.

Sterilization.-This term implies that all microbial forms have been removed or destroyed. In the past, liquid disinfectants were widely used in an attempt to sterilize surgical instruments, particularly scalpels, hypodermic syringes, and needles. It is doubtful whether any such process, except prolonged exposure of scrupulously clean instruments to alcohol-formalin mixtures or strong solutions of halogens, can be relied upon to kill all microbes, including spores; " cold sterilizing solutions" are rapidly being superseded by physical means such as steam, dry heat, or irradiation (Kelsey, 1964).

Disinfection.-This term, which implies the virtual elimination of harmful microbes (generally with the exception of spores) with the object of preventing the transmission of disease, is used in hospitals for four main purposes: (1) to make contaminated objects safe for further use, (2) to reduce the microbial contamination of the inanimate environment or (3) of the skin of hands or operation sites, and (4) to prevent bacterial growth.

\section{(a) To Make Contaminated Objects Safe for Further Use}

Faeces, urine, pus, and other body discharges are a potential source of danger to those who must handle them or objects contaminated with them. It will of ten be possible (and always preferable) to disinfect such objects by heat, but there will probably always remain situations where liquid disinfectants must be used. For this application the disinfectant chosen should have a wide antibacterial spectrum and should not be seriously inactivated by organic matter; the disinfecting-time need not be particularly short, as 10 to 30 minutes can readily be allowed without inconvenience.

There are a limited number of occasions when an instrument used in surgery must be free from specific pathogens but need not necessarily be sterile. Such are cystoscopes and specula used for the examination of the nose, throat, ear, or vagina. These may be cleaned and immersed in a liquid agent that will destroy vegetative organisms, possibly including mycobacteria, but generally not spores. The success of this procedure depends on scrupulous cleaning and precautions to ensure that all parts of the instruments are exposed to the liquid for a sufficient time. Such instruments are now being designed so that they can be subjected to heat treatment sufficient either to sterilize or at least to pasteurize them. One instrument which cannot be so treated is the clinical thermometer, for which a suitable liquid disinfectant must still be used.

Infants' feeding-bottles are sometimes disinfected chemically ; but here again heat treatment is becoming more common, especially in hospital practice.

Medical laboratories use jars of disinfectant into which contaminated slides, instruments, and pipettes may be discarded. Such objects can be safely washed after a reasonable time.

\section{(b) To Reduce the Microbial Contamination of the Inanimate Environment}

The extent to which the hospital environment is contaminated by microbes may influence the incidence of cross-infection, and it is therefore reasonable to try to reduce this contamination by cleaning and by disinfecting. There can be no doubt that a clean hospital is safer than a dirty one, but there is no convincing evidence that the use of disinfectants adds much to really effective cleaning. For example, Finegold et al. (1962) made bacterial counts on floors after they had been washed either with detergents alone or with relatively concentrated disinfectant solutions and found no significant difference. Vesley and Michaelsen (1964) found that adding disinfectants to the solutions used for cleaning floors neither increased the reduc- tion in bacterial flora immediately afterwards nor influenced the rate at which the floor-counts were subsequently built up again. It is probable that bacteria on vertical surfaces, such as walls, are held there by electrostatic forces and are not likely to be easily dislodged. Even when dust which contains bacteria is resuspended from the floor this is only a part of the airborne load and may well be overshadowed by what comes from other ward activities.

From time to time claims have been made that certain disinfectants have a continuing antibacterial action when applied to surfaces such as paints, polishes, or in cleaning solutions. The only claim which the Committee considers to be firmly based is that of Kingston et al. (1962) for resins and paints containing compounds which slowly emit formaldehyde, but, as these authors point out, "it is rash to assume that such treatments would have any useful effect in reducing the spread of disease."

Terminal disinfection of wards and cubicles is becoming less common and is very sparingly recommended by the American Public Health Association (1960) in their handbook on the Control of Communicable Diseases; this handbook is also accepted by the health authorities in Great Britain. Smallpox is a very special case and is dealt with in a recent official memorandum (Ministry of Health, 1964). See also Appendix 2 to this report.

Despite this tendency to reduce the use of disinfectants for household purposes within hospitals they will always be needed for occasions when floors, walls, or furniture are known to have been contaminated, or for use in areas of special risk such as water-closets, operating-rooms, nurseries, or intensive-care units. They may also be used in hospital kitchens for surfaces on which food is prepared.

It is doubtful whether disinfectants are necessary for sinks, sluices, or drains ; these are probably best kept hygienic by good design and by regular cleaning.

Baths may be a source of cross-infection. The most important single preventive measure is thorough cleaning. Abrasive powders containing hypochlorites are now available which when used in accordance with the makers' instructions will not only clean but will also disinfect. A clear soluble fluid of the improved lysol type (see Section 5) used undiluted or the mixture of hypochlorite and detergent suggested by Boycott (1956) may also be used. The practice of adding an emulsion of hexachlorophane to the bathwater as described by Ayliffe et al. (1959) is expensive and is more of a clinical than a disinfecting procedure.

\section{(c) For the Skin of Hands or Operation Sites}

In this application disinfectants are used to kill microbes or to prevent their growth on skin, mucous membranes, or other living tissues. They are applied to the hands of surgeons and assistants to reduce the risk of wound contamination through undetected punctures in their gloves, and to the skin of patients at the sites of incision. Transient organisms are relatively easily dealt with by the mechanical effects of the washing and by the disinfectant used but organisms resident in the depths of the skin may prove difficult or impossible to remove completely. Staphylococcus aureus may be one of these organisms and presents an obvious risk. In recent years disinfectants have been developed which, when used constantly in the form of handcream or soap, impart a lasting antibacterial quality to the skin itself ; this method reduces the numbers of bacterial residents and-even more important-it virtually eliminates staphylococci.

Antimicrobial agents are also used to prevent the infection of mucous membranes, as lubricant creams or jellies for vaginal examination and for urethral catheterization. They are also used in the treatment of wounds, especially those contaminated with dirt ; but this application is becoming less common. 


\section{(d) To Prevent Bacterial Growth}

In the past, disinfectants have been used to prevent the growth of microbes in the buckets in which cleaning-mops and brushes are stored. This practice is fast falling into disrepute, as better methods of cleaning are being developed. The same can be said for the use in operating-rooms of Cheatle's or other transfer forceps kept in jars of disinfectant. Where these methods must remain-and they should not be countenanced except as a short-term temporary measure-the disinfectant used should have a wide antibacterial spectrum and should be active in the presence of organic matter.

[Note: In this section we have employed only the two terms "sterilization" and " disinfection." We consider that the term " antiseptic" commonly used for a disinfectant applied to living tissues is ambiguous and unnecessary. The term "sanitize" implying the reduction of the microbial flora to an acceptably low level may have a place in food hygiene but is not appropriate in this communication.]

\section{Categories of Disinfectant}

The following categories would therefore appear to be needed in hospital practice.

General Disinfectants.-These should have a wide spectrum, and at appropriate dilutions should remain active in the presence of organic matter. They should be used for such purposes (where they are considered really necessary) as washing down premises, steeping linen, transporting contaminated instruments, storing mops, neutralizing spilt discharges, or for laboratory discard purposes. The main purpose here is not necessarily to kill all organisms throughout the whole substance of the contaminated object ; it will often be enough to make the surface of the object and the liquid phase free of significant numbers of organisms-for example, disinfection of faeces.

Surface Disinfectants. - These should have a wide spectrum, be quick-acting, be non-injurious to materials, and leave no objectionable residue. They should be used for the rapid disinfection of clean surfaces such as trolley tops, kitchen tables, and clinical thermometers.

Disinfectants for Use on Skin or Mucous Membranes.-Used in situations where they may come into contact with living tissues.

\section{Some Disinfectants in Common Use}

\section{(a) Simple Organic Disinfectants}

Alcohols.-Ethyl alcohol in the form of industrial methylated spirits is the alcohol most commonly used for skin disinfection; it can also be used for disinfecting inanimate clean surfaces. Ethyl alcohol is lethal in a period of seconds to all types of non-sporing bacteria on scrupulously clean surfaces, but when applied to the skin and other surfaces its activity disappears as the alcohol dries off. It is almost devoid of activity against bacterial spores but will inactivate viruses, although owing to the nature of the environment in which the viruses are usually found this may take several hours. In the presence of blood, pus, and similar material the efficacy of ethyl alcohol is much reduced, and for this reason, as well as for its lack of sporicidal activity, it is not recommended for sterilizing instruments but can be used for disinfecting clean clinical thermometers; the immersion-time should be not less than 10 minutes. The optimum concentration for the use of ethyl alcohol on dry surfaces is in the region of $70 \%$ with water. Its activity falls away rapidly below about $50 \%$, and if working dilutions are left in unstoppered bottles their strength can rapidly be reduced by preferential evaporation. For the same reason it should be used undiluted on wet surfaces.
Isopropyl alcohol (isopropanol) is a more active bactericide when used at the same concentration and rather less sensitive to dilution. It has the added advantage of being unpalatable and exempt from excise control. As it is a more powerful fatsolvent it should be used with caution on skin, and it cannot be recommended for repeated use, as for surgeons' hands. It may also be irritant to the eyes.

Acetone has only mild antibacterial properties and there is no point in adding it to alcohol for skin disinfection.

Ether is only weakly bactericidal and is not recommended for skin treatment.

Formaldehyde, either in solution or in the vapour phase, is an effective germicide, but its pungency and irritancy severely limit its use. As a vapour it is used for disinfecting blankets, bedding, and other materials and for the terminal disinfection of cubicles (see Appendix 2). Solutions containing 5 to $10 \%$ of formaldehyde in alcohol are slowly sporicidal and have been used for instrument sterilization. To prevent rusting $0.2 \%$ sodium nitrate or $2.5 \%$ borax should be used.

Glutaraldehyde has been suggested by workers in the U.S.A. and in Australia (Pepper and Chandler, 1963 ; Stonehill et al., 1963 ; Rubbo and Gardner, 1965) for disinfecting heat-sensitive instruments. Its activity is similar to that of formaldehyde but its low volatility makes it less unpleasant in use. Freshly prepared, specially buffered solutions have to be used. It is as yet too early to say what role this agent may have in hospitals.

\section{(b) The Halogens}

Hypochlorites are effective against a wide variety of organisms, including viruses, but they have less activity against spores and none against mycobacteria. They are inactive in the presence of organic matter and may be unstable unless carefully formulated. Because they are relatively non-toxic they are used extensively in the dairy and food industries. They may damage some surfaces, such as aluminium, and bleach many fabrics. They fail to wet greasy or highly polished surfaces, and so are entirely ineffective unless combined with surface-active agents such as soap or detergents. The Ministry of Agriculture, Fisheries and Food publish a list of hypochlorite preparations which are approved for potency and stability under the Milk and Dairy (General) Regulations, 1959.

Iodine in aqueous or alcoholic solution is probably the most effective germicide available. An aqueous solution is rapidly lethal not only to vegetative bacteria but also to spores. Alcoholic solutions are outstanding as skin disinfectants, but they leave stains which are hard to remove and may be irritant to the skin of some individuals.

The iodophores, which are becoming available under a variety of trade names, depend for their activity on the slow release of iodine from combination with anionic detergents. They are said to be relatively non-toxic and to have some detergent properties. Lowbury et al. (1964b) and others have reported favourably on their use for skin disinfection, but their cost and sensitivity to organic matter probably limit their more general use.

\section{(c) Phenol and Related Substances}

Phenol could well be replaced by other more effective, less toxic, and often much cheaper substances. It should no longer be used for general disinfection although it has certain specialized uses (see Section $8 \mathrm{~b}$ ). Its highly toxic vapour has only very mild antibacterial properties and has no place in practical disinfection.

Chloroxylenol is available as the solution of chloroxylenol B.P.C. and a variety of commercial preparations of which Dettol was the first to be described in the United Kingdom. 
They were introduced for combating pyogenic infections on the skin, and this remains their primary purpose. They are active against the streptococci, but at the dilutions generally recommended they are almost inactive against some Gram-negative organisms, notably the pseudomonads, which may actually multiply in quite strong solutions. Their activities are greatly reduced in the presence of blood, pus, or other organic matter. They are not recommended as general disinfectants.

Chlorhexidine is relatively non-toxic but it is more effective against Gram-positive than Gram-negative organisms. It is inactive against mycobacteria and spores. In alcoholic solution it is a useful skin disinfectant and it has several clinical uses, but it is not recommended for household use both because of its selective action and its cost.

Hexachlorophane is another antibacterial agent which is active mainly against Gram-positive organisms. In hand creams or in soaps it has been recommended for hand and skin disinfection, and in powders it is useful for application to the umbilical stumps of newborn babies. Repeated treatment over several days is necessary with hexachlorophane preparations: after a single treatment the effect is comparatively small.

Thymol has only a low solubility in water and is a poor bactericide. Its use as a disinfectant even for clinical thermometers is not recommended.

\section{(d) Coal-tar Fluids}

The disinfectants of this group contain coal-tar acids or similar acids derived from petroleum. They comprise not only the well-known black and white fluids but also the lysols and the more sophisticated clear soluble fluids. They are made with different distillation fractions which differ in their bactericidal activities. They are all effective disinfectants, and, apart from those which have been "modified" by such items as chlorinated phenols, are not bacteriologically selective and are resistant to inactivation by organic matter. They are only weakly active, if at all, against spores.

These disinfectants are normally assessed by the traditional phenol coefficient methods, such as the Rideal-Walker and Chick-Martin tests, and for lack of anything better it is on this basis that the concentration at which they should be used is at present determined.

Lysol and Its Allied Preparations.-The lysols are made by dissolving in various soaps the mixed cresols, which are among the lowest-boiling coal-tar fractions. They are good disinfectants for general purposes; care is needed in handling them because of their irritant and corrosive properties. This objection has been largely overcome by the introduction of various clear soluble fluids which, while keeping the same basic formulation, employ much more carefully selected and controlled cresol fractions. It has been stated that such preparations can be applied to the skin neat.

Black and White Fluids.-These two types of fluid contain similar coal-tar fractions but differ in the way they are formulated. For general disinfection purposes the white fluids are preferred before the black ones, being more stable on dilution and less affected in this respect by salt and other substances. If such disinfectants are required it is wise to buy only those which comply with British Standard Specifications 2462:1961.

\section{(e) Surface-active Disinfectants}

Ampholytic Surface-active Agents. - The active compounds in this group are synthetic amino-acids of high molecular weight which combine detergency in the anionic group with bactericidal power in the cationic moiety. Probably the best known of the commercial preparations are the tego products, of which there are several. They are said to be active against both Gram-positive and Gram-negative bacteria but are not sporicidal. They are used in dairy disinfection, but favourable accounts of their use in hospitals have yet to be confirmed. For this reason and because they are expensive we cannot recommend them at present.

Quaternary ammonium compounds are widely used in the dairy and food industries for disinfecting containers and utensils, but in medicine they have only a very limited application as cleansing agents for skin or mucous membranes. They can destroy the Gram-positive bacteria but they are much less effective against the mycobacteria and Gram-negative organisms, notably the pseudomonads, and are without action against spores. They are reported to be active against some groups of viruses (see Section 8b).

\section{(f) Miscellaneous}

Hydrogen peroxide is not now recommended as a general disinfectant for use in hospitals.

Mercury Compounds.-There is now little place in hospital practice for the inorganic mercury compounds, as they are too toxic. The organic compounds, such as phenyl mercuric nitrate, are bacteriostatic rather than bactericidal ; they are also considerably affected by organic matter. Their main value is as preservatives in injections and other pharmaceutical preparations and in preventing the contamination of the humidification systems of babies' incubators.

Pine disinfectants have some usefulness as deodorants but have little value as disinfectants. They are not recommended for use in hospitals.

\section{Tests for Disinfectants}

There are several reasons why disinfectants need to be tested, and the many tests which have been proposed indicate that no generally accepted set of tests has yet been designed.

Tests are needed for the routine quality control of a formulated product in the factory or by a purchasing agency. The chief requirement of such "buying and selling" tests is reproducibility in standard conditions rather than any direct relation to operational use. For phenolic disinfectants the Rideal-Walker and Chick-Martin tests have been in use for many years. These are essentially bio-assays in which the performance of an unknown fluid is compared with that of a pure phenol standard solution. The less the test fluid resembles phenol the less valid the test becomes, as it cannot be assumed that the two agents will behave similarly in respect to different conditions of dilution, $p \mathrm{H}$, temperature, sensitivity to organic matter, or antimicrobial spectrum. If this criticism is true for the use of a phenol standard with phenolic disinfectants it is obvious that the not uncommon practice of assigning phenol coefficients to disinfectants of entirely different types is entirely indefensible.

Although the limitations of these tests are well understood and many attempts have been made to improve upon them, no really satisfactory and generally acceptable alternatives are yet available. Work in this field continues and the Committee understands that some progress is being made.

Tests based on bacterial counts are sometimes used for nonphenolic disinfectants. Examples are the Germicidal and Detergent Sanitizer Test-Official (Association of Official Agricultural Chemists, 1960) or that laid down in B.S.3286 for quaternary ammonium compounds.

These tests must be supplemented, where appropriate, by tests for stability in various storage conditions, such as those provided for black and white fluids in B.S.2462. Even so, these tests do not in themselves give any assurance that a disinfectant is suitable for any particular purpose. Claims such as " 1,000 
times stronger than pure carbolic by the R.W. test " may deceive the housewife but should not impress those for whom this report is intended.

Several " in use" tests have been devised which are intended to simulate practical situations, and groups of such tests have been used by official bodies for preparing lists of approved disinfectants. Two such test structures are that of the German Society for Hygiene and Microbiology (Kliewe et al., 1958) and that of the Association of Official Agricultural Chemists (1960), which is widely used in North America. Less officially there are many tests used by individual workers for their own specific needs or by manufacturers to emphasize the merits of their own products.

Most of these tests can be criticized on several grounds: they may be unrealistic, test organisms may be used which are relatively easy to kill, and many which are claimed to be tests for surface disinfection fail to distinguish between disinfectant and detergent activity, and few are reproducible. At best these tests define the usefulness of the disinfectant in a very restricted field ; unless the purpose for which it is to be used very closely resembles the conditions of the test the results will have little significance. Some have tried to evaluate disinfectants used for housekeeping purposes by bacterial counts of surfaces, solutions, or air. These procedures are laborious and technically difficult; they may possibly yield useful information about the connexion between environmental contamination and clinical sepsis, but few would consider them the method of choice for the purpose of disinfection.

The potency of some disinfectants, such as the hypochlorites, can be chemically determined, and generally accepted usedilutions have been worked out by years of experience in several fields.

Where such disinfectants cannot be considered and a phenolic disinfectant is indicated, experience has shown that the ChickMartin coefficient can be employed to arrive at a use-dilution provided that only known broad-spectrum fluids are used.

The Rideal-Walker test has been used for many years for quality control, but by itself it gives no indication of the suitability of a disinfectant for any particular purpose. It is not unknown for a fluid to be arbitrarily rejected because its R.W. coefficient does not meet some traditional value, although its C.M. coefficient is satisfactorily high.

On these premises the Committee bases the following practical recommendations, but its members hope that those who have the resources will undertake further work which will result in generally agreed tests for quality control and for antimicrobial spectrum being developed before long.

\section{Disinfectants in Practice}

General Disinfectants.-There is at present no test or set of tests generally recognized as entirely satisfactory for this category of disinfectant. The Committee believes that only certain phenolic disinfectants can be relied upon in this application as having a wide antimicrobial spectrum and as not being seriously inactivated by organic matter. They are discussed in Section 5 and detailed recommendations for their use are given in Appendix 2.

Surface Disinfectants.-For many purposes general disinfectants could be used. Other suitable disinfectants are the alcohols and hypochlorites, the latter being particularly suitable for surfaces on which food is processed. Ethyl and isopropyl alcohols should be used in $70 \% \mathrm{w} / \mathrm{w}$ solution. Hypochlorites approved by the Ministry of Agriculture, Fisheries, and Food should be used at a concentration of 200 to 250 p.p.m. of available chlorine. On surfaces which are known to be only slightly contaminated with bacteria or dirt, such as stainless steel or glass trolley-tops which have been protected by a towel and have not been visibly soiled, 50 p.p.m. is sufficient provided that the surface is thoroughly wetted. If necessary, soap, soda, or detergent may be added (see Section 5a).

Skin Disinfectants.-For the pre-operative treatment of the skin of surgeons' hands or operation sites the Committee considers that it cannot do better than to refer readers to the recommendations of Lowbury and his co-workers which are summarized in Appendix 2 or to the article on antiseptics (Brit. med. F., 1964).

Antimicrobials intended for use on mucous membranes or wounds should be chosen on clinical grounds.

\section{Two Special Cases Require Separate Discussion}

(a) Mycobacteria.-In disinfecting discharges from tuberculous patients, or objects that may be contaminated with these discharges, every effort should be made to use adequate heat treatment. When this is impossible, and only then, one of the phenolic disinfectants recommended for general disinfection should be used in the stronger of the concentrations recommended in Appendix 2 and for a prolonged period, preferably 24 hours.

(b) Viruses.-There should be few occasions when liquid antiviral agents need be used in hospitals, apart from their specialized use in laboratory discard jars. Information about the relative effectiveness of different disinfectants against viruses is very incomplete, but what is available suggests that the halogens, such as hypochlorites and some iodine preparations, are effective against all groups of viruses and thus would seem to be the agents of choice except in the presence of large amounts of organic matter. Quaternary ammonium compounds and the more refined phenolic preparations appear to be active against the lipophilic viruses, such as herpes, vaccinia, influenza, and adenoviruses, but very much less active against the hydrophilic viruses, such as poliovirus, the Coxsackie group, and the E.C.H.O. group. Pure phenol in aqueous solution has been reported as effective against all groups tested, and so it is probably the agent of choice when much organic matter is present (Klein and Deforest, 1963 ; Armstrong and Froelich, 1964).

\section{Conclusions}

There are few genuine indications for the use by hospitals of liquid chemical disinfectants, and even these few needs can be met by a small number of agents.

Detailed recommendations can be made only by those who will have the task of justifying them to their colleagues and the responsibility of implementing and, if necessary, enforcing them. The Committee hopes that the advice here given, which must at present be somewhat general, will make this arduous and unenviable task easier.

A final suggestion may be permitted. Although complete uniformity of practice within British hospitals is unlikely, it is not unrealistic or impossible to produce a disinfectant programme common to a hospital group or even to a region: where this has been done much economy of effort and material has been achieved. The Committee hopes that this challenge will result in the early publication of a number of such programmes.

The Committee's thanks are due to all those in hospitals who completed the questionaries, to those in the Supplies Division and Statistics Branch of the Ministry of Health who analysed the completed forms, and to many others who provided much-needed help and encouragement, particularly Professor A. M. Cook, Surgeon Commander H. M. Darlow, Dr. E. J. L. Lowbury, Mr. C. A. Scarlett, and Mr. A. H. Walters. 


\section{Appendix 1 : Survey of Disinfectant Usage}

The following table shows the popularity of disinfectants for various purposes, as indicated by the number of times mentioned in the reply to the questionary.

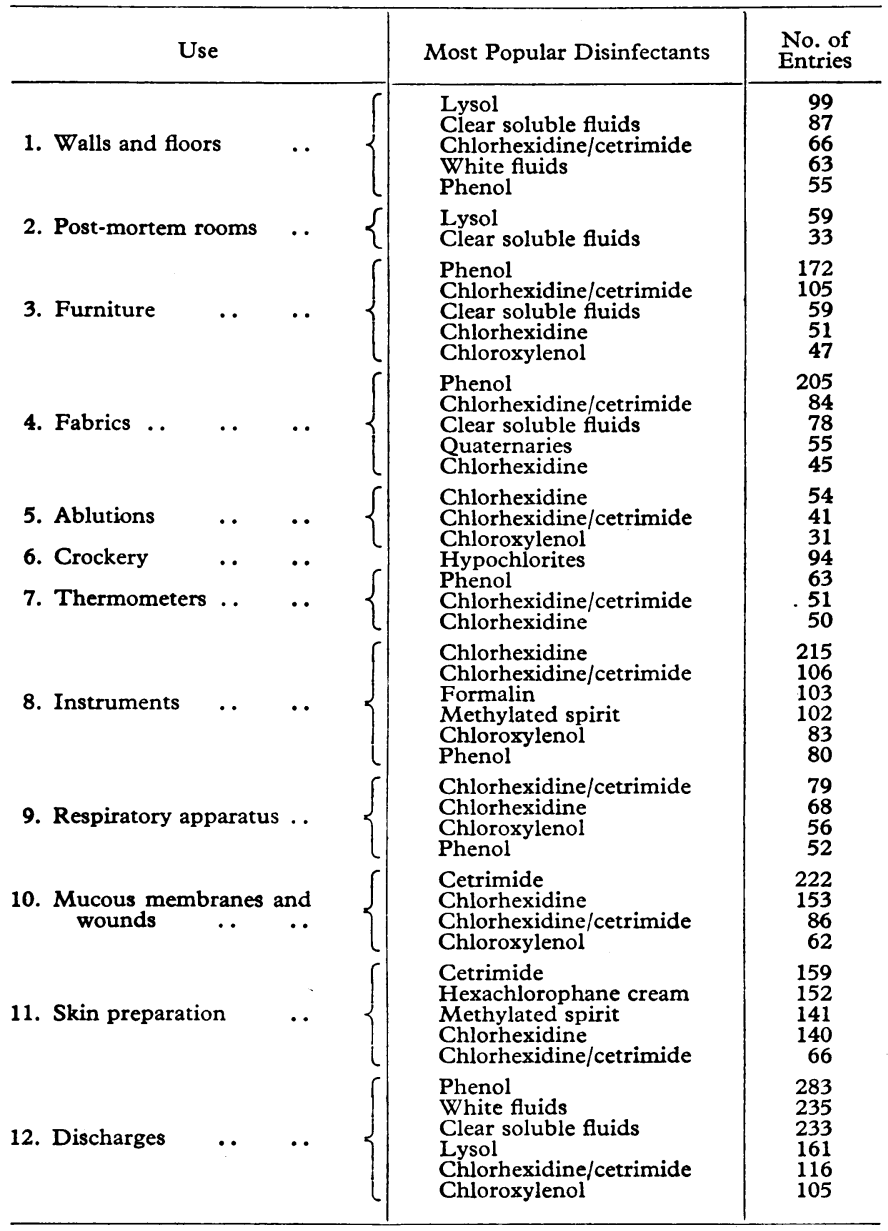

Appendix 2 : Recommended Disinfectants for Hospital Use

\section{General Disinfection}

$A$ phenolic disinfectant based on coal-tar acids derived from tar or petroleum - such as a black or white fluid to B.S.2462 or a clear soluble fluid of the lysol type (but not chlorinated phenols) having a Chick-Martin coefficient of at least 1.5.

For general purposes in clean situations use at a dilution of not more than 50 times the C.M. coefficient. (For example, a white fluid to B.S.2462 type WG having a C.M. coefficient of 4.4 should not be used in a weaker solution than 1 in 220.)

If contamination with organic matter is heavy, as when blood, pus, or faeces are present, a dilution of not more than 20 times the C.M. coefficient should be used.

The choice of fluid will depend on toxicity, compatibility, stability, and cost. If it is intended to add a detergent to the phenolic fluid the makers should be consulted about possible incompatibility.

\section{Surface Disinfection of Clean Objects}

Hypochlorites (approved by the Ministry of Agriculture, Fisheries, and Food) with or without added detergent at a concentration of
200 to 250 p.p.m. For the repeated, ritual treatment of smooth hard surfaces such as stainless steel or glass trolley-tops a concentration of 50 p.p.m. will suffice if thorough wetting is ensured (see Section $5 b$ ).

Inciustrial methylated spirit $70 \%$ or isopropyl alcohol $70 \%$.

\section{Disinfection of the Skin of Hands or Operation Sites}

(Quoted from Lowbury et al., 1960̄a, 1960b, 1963, 1964a, 1964b.)

Operation Sites.-A single application of chlorhexidine ( $0.5 \%)$, iodine $(1 \%)$, or laurolinium $(5 \%)$ in $70 \%$ industrial methylated spirit. Repeated washing with hexachlorophane liquid soap or polyvidone iodine followed by pre-operative treatment with alcoholic chlorhexidine.

Injection or Venepuncture.-Aqueous or alcoholic solutions of chlorhexidine or laurolinium.

Hands.-Repeated washing with liquid soap or cream containing hexachlorophane (3\%) or regular rinsing with aqueous chlorhexidine $(0.5 \%)$.

For detailed recommendations the original papers should be consulted.

See also the article on antiseptics (Brit. med f., 1964).

\section{Terminal Disinfection of Cubicles}

Usually thorough airing and cleaning will be sufficient. If necessary, surfaces may be washed with one of the phenolic disinfectants suggested in paragraph 1 or with hypochlorites. On the rare occasions when fumigation is required the method described by the Formaldehyde Disinfection Committee (1958) should be used. Pulmonary tuberculosis and smallpox present special problems. For smallpox the Memorandum of the Ministry of Health and Scottish Home and Health Department (1964) should be consulted. See also the handbook of the American Public Health Association (1960) for general guidance about preventive measures against communicable diseases.

\section{REFERENCES}

American Public Health Association (1960). Control of Communicable Diseases in Man, 9th ed. New York.

Armstrong, J. A., and Froelich, E. J. (1964). Appl. Microbiol., 12, 132. Association of Official Agricultural Chemists (1960). Official Methods of Analysis, 9th ed. Washington, D.C.

Ayliffe, G. A. J., Alder, V. G., and Gillespie, W. A. (1959). Lancet, 2, 456.

Boycott, J. A. (1956). Ibid., 2, 678.

Brit. med. f., 1964, 2, 1513.

Finegold, S. M., Sweeney, E. E., Gaylor, D. W., Brady, Doris, and Miller, L. G. (1962). Antimicrobial Agents and Chemotherapy, p. 250 .

Formaldehyde Disinfection Committee (Public Health Laboratory Service) (1958). Mth. Bull. Minist. Hlth Lab. Serv., 17, 270.

Kelsey, J. C. (1964). Hosp. and Hith Mgmt., 27, 606.

Kingston, D., Lidwell, O. M., and Noble, W. C. (1962). Mth. Bull. Minist. Hlth Lab. Serv., 21, 246.

Klein, M., and Deforest, A.' (1963). Chem. Spec. Mfrs Ass. Proc. midyear Mtg., 49, 116.

Kliewe, H., Heicken, K., Schmidt, B. H., Wagener, K., Wüstenberg, J., Ostertag, H., Grün, L., Lammers, Th., and Mülhens, K. (editors) (1958). Zbl. Bakt., I. Abt. Orig., 173, 307.

Lowbury, E. J. L., and Lilly, H. A. (1960a). Brit. med. f., 1, 1445.

Lowbury, E. J. L., and Lily, H. A. (1960a). Brit.

- and Bull, J. P. (1960b). Ibid.,

$--(1963)$. Ibid., 1, 1251.

- (1964b). Ibid, 2, 531 .

Ministry of Health and Scottish Home and Health Department (1964). Memorandum on the Control of Outbreaks of Smallpox. H.M.S.O., London.

Pepper, R. E., and Chandler, V. L. (1963). Appl. Microbtol., 11, 384.

Rubbo, S. D., and Gardner, Joan S. (1965). A Review of Sterilization and Disinfection, pp. 141, 244. Lloyd-Luke, London.

Stonehill, A. A., Krop, S., and Borick, P. M. (1963). Amer. F. Hosp. Pharm., 20, 458

Vesley, D., and Michaelsen, G. S. (1964). Hlth Lab. Sci., 1, 107.

\section{General REAding}

Sykes, G. (1965). Disinfection and Sterilization, 2nd ed. Spon, London. 